\title{
Meteorological conditions over Antarctic blue-ice areas and their influence on the local surface mass balance
}

\author{
Righard Bintanja, Garleen H. Reijmer \\ Institute for Marine and Atmospheric Research, Utrecht University, 3508 TA Utrecht, The Netherlands
}

\begin{abstract}
This paper addresses the causes of the prevailing meteorological conditions observed over an Antarctic blue-ice area and their effect on the surface mass balance. Over blue-ice areas, net accumulation is zero and ablation occurs mainly through sublimation. Sublimation rates are much higher than over adjacent snowfields. The meteorological conditions favourable for high sublimation rates (warm, dry and gusty) are due to the specific orographic setting of this blue-ice area, with usually a steep upwind mountainous slope causing strong adiabatic heating. Diabatic warming due to radiation, and entrainment of warm air from aloft into the boundary layer augment the warming. The prevailing warm, dry conditions explain roughly $50 \%$ of the difference in sublimation, and the different characteristics of blue ice (mainly its lower albedo) the other $50 \%$. Most of the annual sublimation $(\sim 70 \%)$ takes place during the short summer (mainly in daytime), with winter ablation being restricted to occasional warm, dry föhn-like events. The additional moisture is effectively removed by entrainment and horizontal advection, which are maximum over the blue-ice area. Low-frequency turbulent motions induced by the upwind mountains enhance the vertical turbulent transports. Strong gusts and high peak wind speeds over blue-ice areas cause high potential snowdrift transports, which can easily remove the total precipitation, thereby maintaining zero accumulation.
\end{abstract}

\section{INTRODUGTION}

Blue-ice areas (BIAs) are known as the ablation "islands" of the Antarctic ice sheet, occupying only about $1 \%$ of its surface area. They are located mostly in the vicinity of rock outcrops (Bintanja, 1999). Less is known as to why these spots favour a negative surface mass balance. Since the surface mass balance of a region is determined primarily by the prevailing meteorological conditions, this study focuses on the relation between the specific weather characteristics and the surface mass budget of BIAs. We will try to find out the causes of the different surface mass-balance characteristics over BIAs, and we will attempt to quantify these differences where possible.

Antarctic blue-ice areas exhibit a number of peculiar features that are of interest for a wide range of purposes. First, numerous meteorites have been found on Antarctic BIAs, as some BIAs apparently acted as meteorite traps (Cassidy and others, 1992). The bare, rippled ice surface of BIAs was also considered to be useful for airfield purposes (Mellor and Swithinbank, 1989). Ice cores taken from BIAs revealed that very old ice can be exposed at the surface (Fireman, 1989; Nishiizumi and others, 1989; Van Roijen and others, 1995), which may be exploited for palaeoclimatic purposes, because ice exposed at BIAs was formed long ago in a distant accumulation zone and has since flowed towards the BIA (Whillans and Cassidy, 1983). In the last decade, the surface mass-balance distributions and the meteorological conditions over some selected BIAs have been investigated in detail (e.g. Jonsson, 1992; Takahashi and others, 1992; Bintanja and Van den Broeke, 1995c; Van den Broeke and Bintanja, 1995b; Bintanja, 1999). A number of meteorological and glaciological charac- teristics typical of BIAs were identified. These include the relatively warm, dry local conditions, the gusty turbulent wind climate, the large sublimation rates, the general decrease in annual ablation rate with elevation and their climate sensitivity (Bintanja, 1999).

In this paper, the focus is on a "standard" BIA, i.e. one located in the lee of a mountain range or nunatak. A typical length scale of such BIAs is $1-10 \mathrm{~km}$ (depending, among other things, on the height of the upwind mountain), the width of the BIA being largely constrained by the width of the upwind mountain. Following Bintanja (1999), we define a BIA as an ablation zone being dominated by sublimation, so that melting can be considered negligible. This is to distinguish BIAs from melt-dominated ablation zones commonly found on glaciers and ice caps all around the globe (and also in the coastal regions of Antarctica). Such high-elevation BIAs have distinctly different radiative, aerodynamic, glaciological and hydrological properties. Generally, ablation regions at elevations higher than about $1000 \mathrm{~m}$ a.s.l. can safely be termed BIAs. However, this definition is sometimes unclear at lower-elevation BIAs, since it is often not known how much of the total ablation is due to melt.

The reasons that meteorological and glaciological conditions over BIAs differ from those over adjacent snowfields at the same elevation can be divided into two main categories: (1) differences in surface characteristics between blue ice and snow, and (2) differences in the topographic setting. The first point relates to differences in albedo, extinction characteristics for solar radiation and surface aerodynamic roughness. The second point deals with the differences in nearby (usually upwind) orography.

In this paper, we will try to identify and, where possible, 
quantify the fundamental underlying mechanisms and causes responsible for the peculiar meteorological conditions over BIAs. We will relate these different conditions to the surface mass-balance processes active over BIAs, and try to find out why they are different over snow. These processes are (1) ablation by sublimation, (2) accumulation by precipitation and (3) accumulation or erosion by drifting snow. We will specify how each of these three processes is affected by the different meteorological conditions and the specific characteristics of BIAs. We will do this on the basis of the detailed and extensive meteorological and glaciological dataset obtained during the 1997/98 summer field campaign to a BIA in Dronning Maud Land, Antarctica, a brief summary of which will be given in the next section.

\section{LOGATION AND MEASUREMENTS}

The BIA in the Scharffenbergbotnen valley (see Fig. 1) is undoubtedly the best-studied BIA from a meteorological and glaciological perspective, since in 1988 the Swedish research station Svea was erected just a few kilometres to the west of the BIA, providing easy access to the central Heimefrontfjella region. A dense net of stakes provided an estimate of the spatial distribution in annual mean ablation rate (e.g. Näslund, 1992), while meteorological conditions over this BIA were first studied by means of an automatic weather station (AWS) (Jonsson, 1992; Bintanja and others, 1997). In summer 1992/93, a detailed meteorological and glaciological experiment was carried out on and around the Scharffenbergbotnen BIA. Seven meteorological stations were deployed and cable-balloon soundings were carried out to investigate in detail the prevailing meteorological conditions over a BIA and its surroundings (Bintanja and Van den Broeke, 1995a-c; Van den Broeke and Bintanja, 1995a, b). This was followed by an even more detailed and

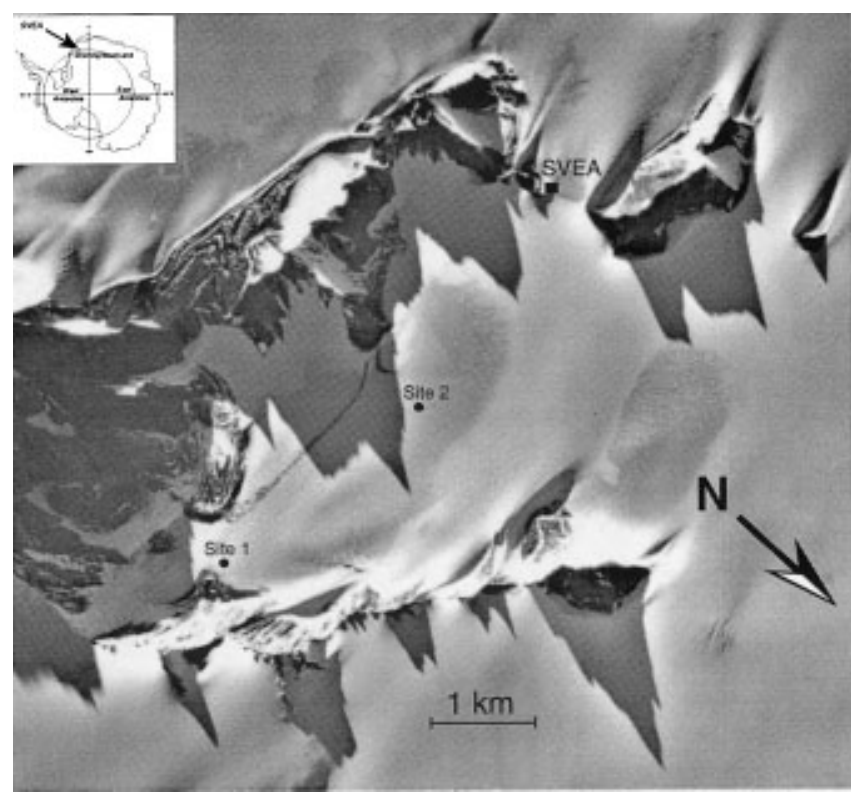

Fig. 1. Aerial photograph of the Scharffenbergbotnen valley, Dronning Maud Land. Dark regions indicate bare rock and moraine, while light regions indicate snow-covered areas. Blue-ice areas are greyish in this picture. Sites 1 and 2 indicate where meteorological measurements have been carried out. Svea is in the western part of the valley. Winds are generally from the east, while the main ice flow is directed southeast into the valley. (Courtesy Institut für Angewandte Geodäsie, Frankfurt). extensive field campaign to the same region in summer $1997 / 98$, results of which are presented in this paper.

Figure 2 shows an outline of the central Heimefrontfjella and the configuration of the experiment. Seven meteorological stations were placed at predetermined sites, three on blue ice (sites 1, 2 and 5) and four over snow. At each station the vertical profiles of wind speed, temperature and relative humidity (at sites 1 and 3 at five levels up to $9 \mathrm{~m}$, at the other sites at three levels up to $6 \mathrm{~m}$ ), wind direction, the shortwave and longwave radiation budgets and subsurface temperatures were measured. A continuous dataset of 37 days was obtained (28 December 1997 to 2 February 1998), during which all sensors of all stations worked simultaneously. Radiosonde soundings were made once or twice a day at Svea, and yielded vertical profiles of temperature, humidity, wind speed and direction throughout the troposphere. A cable-balloon system was used to measure more accurately the vertical profiles in the lowest $800 \mathrm{~m}$. The diurnal cycle in boundary-layer profiles was determined by performing a sounding every $3 \mathrm{~h}$ during 8 days at Svea and one full day near site 1 over the blue-ice area (Bintanja and others, 1998).

Direct turbulence measurements were carried out near sites 1 and 3 on a continuous basis. The various variances and covariances of wind, temperature and humidity fluctuations were determined using fast-response eddy-correlation sonic anemometer and Lyman- $\alpha$ instruments, which sampled at $20 \mathrm{~Hz}$. Additionally, vertical profiles of snowdrift density were measured in the lowest metre of the atmospheric surface layer (at 8, 18, 38 and $80 \mathrm{~cm}$ ) by applying four pulse-counting sensors (Tüg, 1988; Bintanja and others, 2001). Snowdrift measurements were performed near site 1 over blue ice until 25 January 1998, after which the equipment was moved to site 3 where it worked for the rest of the period. At each meteorological profile station stake ablation measurements were carried out at each visit. The easily accessible sites 1-3 were therefore sampled most often (every 2-3 days). Moreover, detailed measurements of the dimensions of the surface ripples of blue ice were carried out (Bintanja and Reijmer, unpublished information). Finally, AWSs were placed near sites 1 and 3 (and at four other locations not relevant here), containing a relatively simple sensor configuration to measure year-round meteorological conditions. Attached to each AWS is an acoustic height sensor, which continuously measures changes in surface height due to accumulation or ablation. The AWS near site 1 stopped providing reliable meteorological data on 30 September 1998 (it was repaired in summer 1999/2000). The acoustic height sensor worked 1 year longer.

In trying to determine how meteorological conditions over blue ice diverge from those over an undisturbed snowfield, we will focus on a comparison between data of sites 1 and 3. These two sites are at about the same elevation (Table 1). Nevertheless, the air over blue ice is significantly warmer and drier than over snow. We will try to explain these differences by looking at variations in meteorological conditions along the transect through sites 7, 6, 1, 2 and 4, which runs from east to west from the high Amundsenisen plateau along the Scharffenbergbotnen BIA towards the lower Ritscherflya plateau (see Fig. 2). This east--west-directed transect is aligned approximately parallel to the prevailing winds, as both geostrophically and katabatically forced winds blow from easterly directions (Bintanja, 2000a). This enables us to roughly follow an "average" air parcel along its typical westerly motion along 


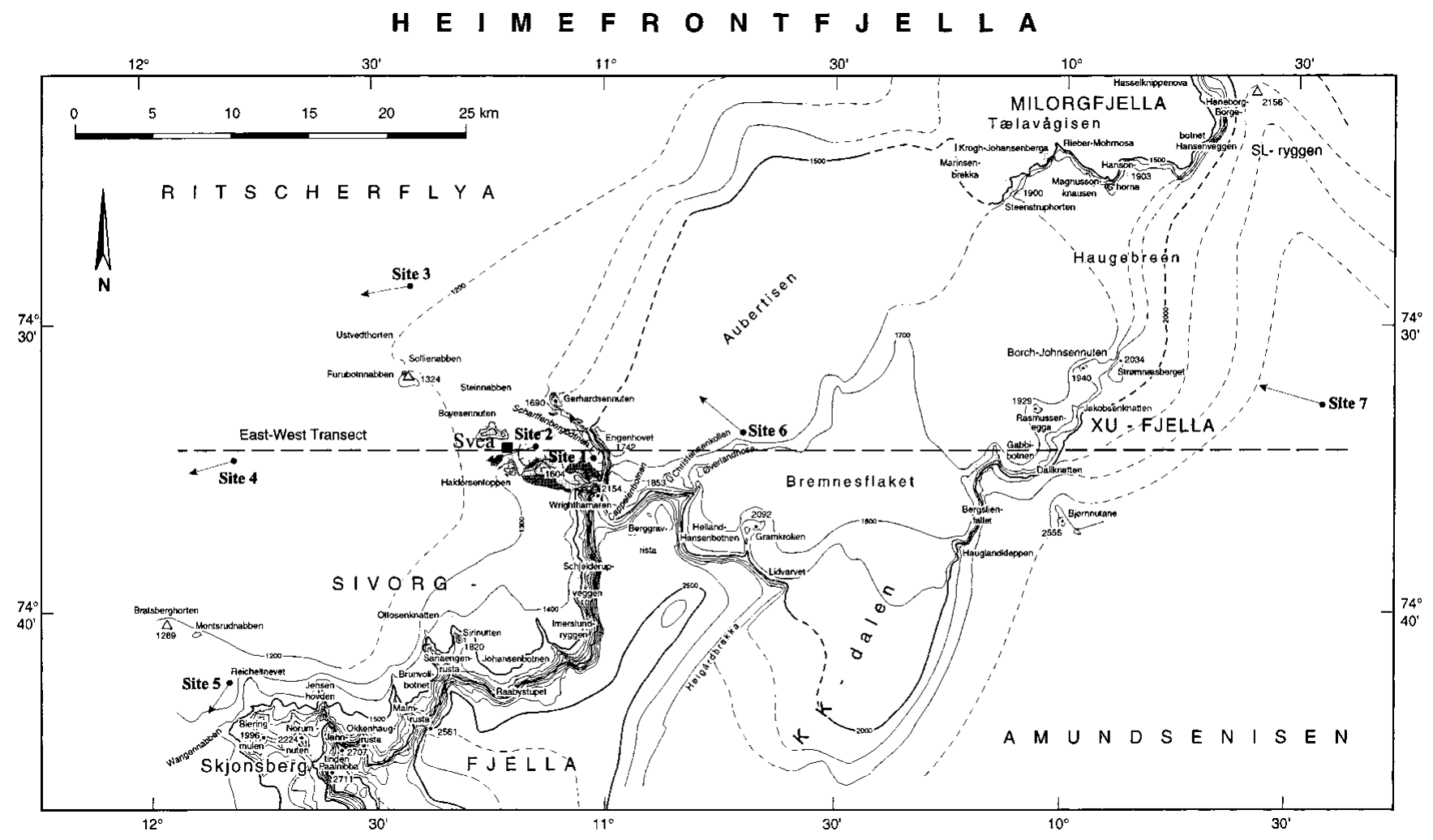

Fig. 2. Map of the central Heimefrontfjella showing the locations of the various measuring sites relative to the Scharffenbergbotnen valley. The dashed line represents the east-west transect approximately running along sites 7, 6, 1, 2 and 4. Arrows at each site indicate the average wind direction during the 37 day measuring period.

a BIA, and infer how its characteristics change along the way. This is done in the next section.

\section{THE MOISTURE BUDGET OF THE ATMOSPHERIC BOUNDARY LAYER}

In this section we will try to explain the observed variations in meteorological variables along the transect crossing the Scharffenbergbotnen BIA (Fig. 2) to find out how the prevailing boundary-layer flow and the BIA interact. Specifically, we will follow an "average" air parcel travelling westward with the prevailing winds along sites 7, 6, 1,2 and 4. Figure 3 shows the variations in surface elevation along this route. The terrain is obviously quite irregular, the $1000 \mathrm{~m}$ descent from site 7 to site 4 being composed of a series of steep slopes, interrupted by some smaller and more gradual ascents. Particularly noticeable is the very steep descent of $>400 \mathrm{~m}$ just upwind of the main BIA at sites 1 and 2.

Figure $4 \mathrm{a}$ and $\mathrm{b}$ show the variation of observed mean temperature $(T)$ and specific humidity $(q)$ over the 37 day measuring period along this transect. Also shown is the temperature of an air parcel moving down adiabatically at a constant potential temperature equal to that of site 7 . Evidently, temperatures are highest over the BIA at sites 1 and 2 , indicating that over blue ice some diabatic warming takes place; this is most likely caused by radiative heating and/or entrainment as slight cooling occurs at the surface by a small downward-directed sensible-heat flux (Table 1). Over snow, the air is cooled diabatically, which is most likely due to the cooling at the surface caused by the strong downward sensible-heat flux. Most of the temperature variations can be explained by adiabatic heating of the air along the transect. Moisture is continuously added to the lowest layers by surface sublimation. Specific humidity is therefore not con- stant, but generally increases during flow down the slope (Fig. 4b). The strongest increases occur over the BIA near sites 1 and 2, suggesting a relatively strong moisture input there. The variations in the fluxes of sensible and latent heat at the surface (Fig. 4c) thus appear to explain, at least quali-

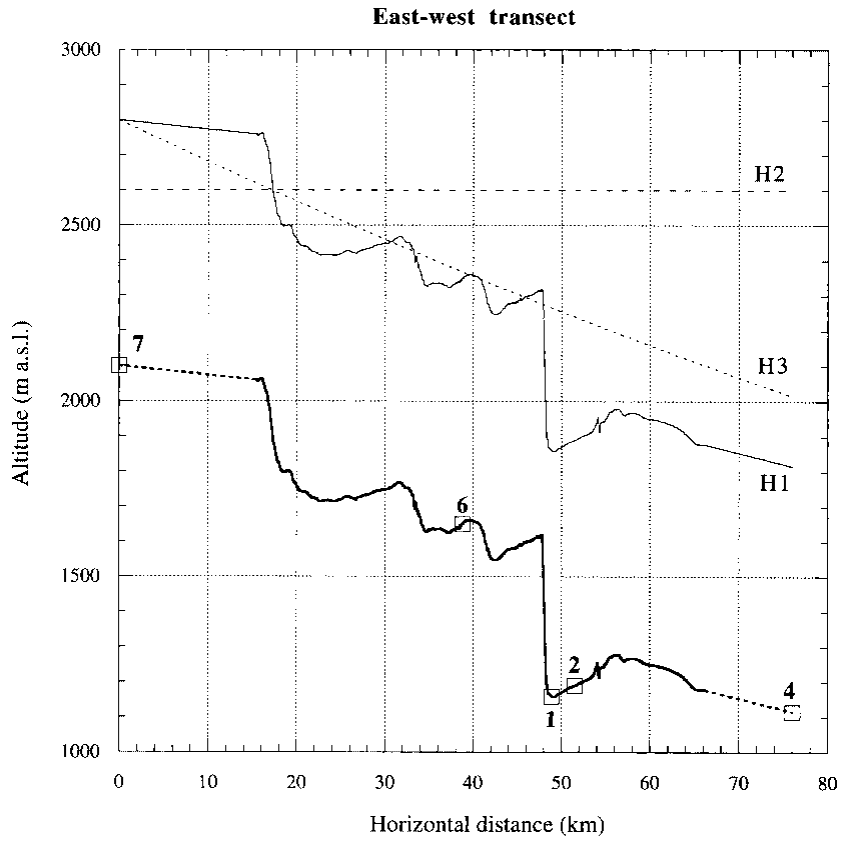

Fig. 3. Surface level profile (thick line) along the east-west transect indicated in Figure 2 according to digital elevation model (DEM) data of the Heimefrontfjella. The stippled lines at both ends indicate linear extrapolations to the elevations of sites 4 and 7 as determined by global positioning system (these regions were not covered by the DEM). Open squares indicate meteorological station positions. Lines H1, H2 and H3 refer to boundary-layer top height scenarios as detailed in the text. 

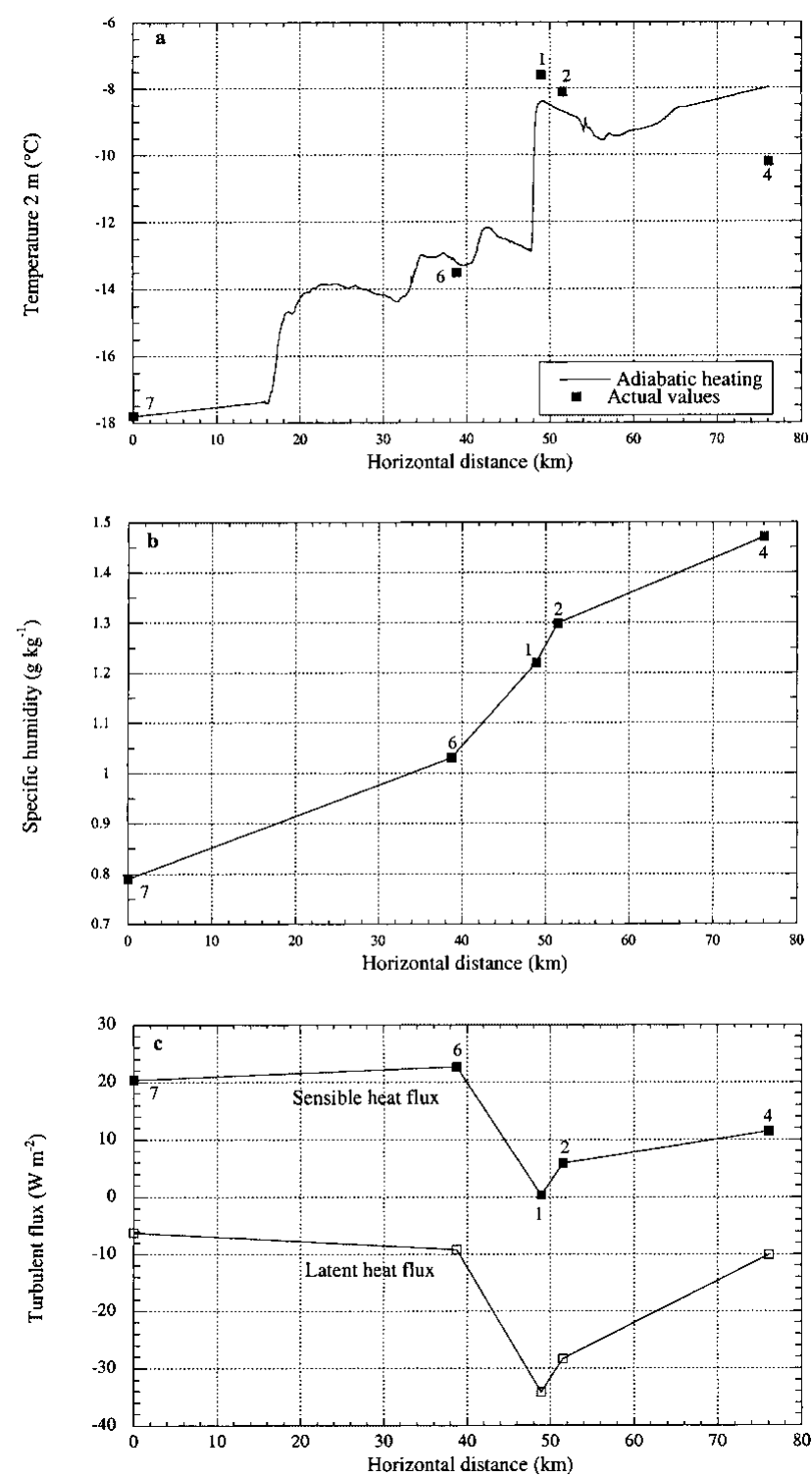

Fig. 4. Variation of 37 day average values of (a) $2 \mathrm{~m}$ air temperature, (b) specific humidity and (c) turbulent sensible-and latent-heat fluxes along the east-west transect. The continuous line in (a) indicates the temperature of an air parcel that is transported adiabatically (constant potential temperature) from site 7 to site 4. Fluxes directed towards the surface are taken positive.

tatively, the observed variations in $T$ and $q$ over blue ice. Cooling of the boundary layer (and heating of the surface) is reduced over blue ice owing to the less stable conditions found there. These, in turn, are caused by the strong radiational heating of blue ice because of its lower albedo, which tends to heat the surface. Latent-heat fluxes clearly peak over blue ice, explaining qualitatively the observed strong increases in specific humidity in the atmospheric surface layer. This indicates that surface sublimation is an important term in the ABL moisture budget. However, spatial variations in entrainment and horizontal advection of moisture may also contribute to the observed variations in $q$.

To infer their importance, a more elaborate analysis of the moisture budget of the boundary layer is applied. To this end, we will assume that the boundary-layer moisture budget along the transect can be described with a simple one-dimensional model. We thus assume that, on average, cross-transect terms are negligible. In steady state, the vertically integrated moisture budget of the boundary layer then is (Van den Broeke, 1996):

$$
\frac{\partial \bar{q} H}{\partial t}=-\frac{\partial \overline{u q} H}{\partial x}-\gamma_{\mathrm{q}} H w_{\mathrm{e}}+\mathrm{LH}_{\mathrm{s}}=0
$$

where $q$ is specific humidity, $H$ is the atmospheric boundarylayer (ABL) depth, $u$ is zonal wind speed, $x$ is the horizontal coordinate along the transect, $\gamma_{\mathrm{q}}\left(=-0.000252 \mathrm{~g} \mathrm{~kg}^{-1} \mathrm{~m}^{-1}\right)$ is the mean vertical specific humidity gradient at the ABL top (determined from radiosonde soundings), $w_{\mathrm{e}}$ is the vertical entrainment velocity and $\mathrm{LH}_{\mathrm{s}}$ is the latent-heat flux at the surface. The overbar denotes vertical averaging over the boundary layer. This simple equation specifies that changes in ABL moisture content are caused by the divergence in horizontal moisture advection along the transect and to the net moisture fluxes at the top of the boundary layer and at the surface. In order to evaluate this balance from the available data of the 37 day measuring period, several assumptions must be made:

(1) At the several sites, only information about surface variables is available. These have been translated into mean ABL values using correlations between surface variables and mean boundary-layer quantities derived from the radiosonde soundings at Svea. Even though such translations will probably not be spatially invariant, we have applied them to all sites to obtain vertically averaged values of wind speed and specific humidity from the surface data.

(2) Since we have no information about spatial variations in boundary-layer depth, three scenarios have been applied (see Fig. 3): (a) H1, a constant ABL depth of 700 m, typical for Antarctic slopes (Kodama and others, 1989); (b) H2, a constant absolute height of the ABL top (2600 m a.s.l.), so that $H$ changes abruptly while going downwind along the transect; and (c) H3, a parabolic profile of the ABL top, which probably represents the most realistic case intermediate between the two "extreme" scenarios.

(3) The entrainment velocity along the transect is evaluated assuming that in steady state it exactly balances the vertical velocity induced by mass divergences/convergences in the ABL: $w_{\mathrm{e}}=\partial \bar{u} H / \partial x$.

Each of these assumptions introduces significant uncertainties, so a quantitative analysis cannot be given with any certainty. It is instructive, however, to look at the budget terms in a qualitative sense. These are presented in Figure 5. The most significant feature is that moisture losses by entrainment and horizontal advection are maximum over blue ice in all three ABL height scenarios. In view of the relatively high specific humidity values over blue ice discussed above, this means that the role of these terms is to efficiently remove the large amounts of moisture in the ABL over blue ice. These high moisture contents are the result of the strong surface sublimation over blue ice, as discussed earlier. Using ECHAM4 atmospheric general circulation model output, Van den Broeke (1997) found that horizontal advection of moisture exhibits the strongest divergences over the steepest parts of the Antarctic ice sheet (such as the Heimefrontfjella). This agrees with our findings to the effect that the advection term is indeed negative and that the largest values are found near the BIA just downwind of the steepest surface slope.

A similar analysis of the heat budget suggests that the ABL over blue ice warms strongly, mainly through entrain- 

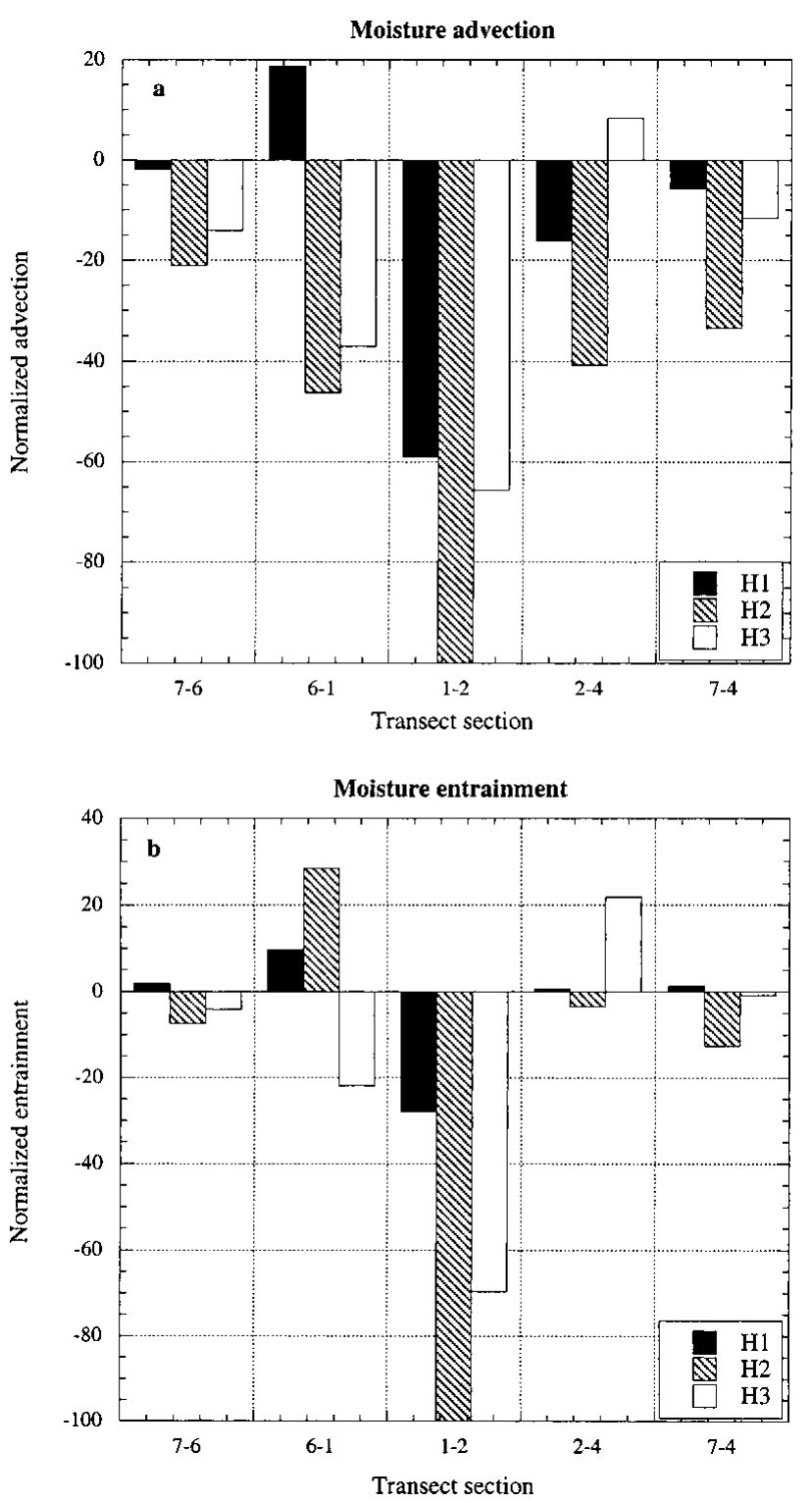

Fig. 5. Non-dimensional moisture-budget terms, scaled with the value obtained using $H 2$ in transect section 1-2. Negative values indicate moisture losses through (a) horizontal advection and $(b)$ vertical entrainment at the boundary-layer top.

ment (not shown). This contributes to low relative humidity values, another favourable condition for high sublimation rates. This warming is in addition to the adiabatic warming shown in Figure 4 and the diabatic warming caused by radiational heating of the low-reflective blue ice and of the surrounding rocks. The combination of these three mechanisms induces warm and relatively dry conditions over BIAs, which contribute significantly to the high sublimation rates found over blue ice. Unfortunately, the observations do not allow us to make a quantitative estimate of how much each of these mechanisms contributes to the anomalous warming of the ABL over BIAs.

These simple calculations provide us with a consistent picture of the moisture budget of the ABL over BIAs. Air flowing down the slope over a BIA warms adiabatically and diabatically, causing high local temperature and low relative humidity values. These conditions, together with the low albedo over blue ice, induce high sublimation rates over blue ice. This increases the moisture content of the ABL over BIAs, which is efficiently counteracted by entrainment and horizontal advection of moisture out of the ABL over blue ice.

\section{METEOROLOGICAL CONDITIONS OVER BLUE- ICE AREAS IN RELATION TO SUBLIMATION}

In this section we will try to determine how the differences in sublimation rate between blue ice (site 1) and snow (site 3) are related to differences in prevailing meteorological conditions and their inherent characteristics. Figure 6 shows mean diurnal cycles of wind speed, temperature, specific humidity, net shortwave and longwave radiation and sensible- and latentheat fluxes. Evidently, the air over blue ice is significantly warmer than over snow at the same elevation, especially at night. It also is much drier in daytime, when relative humidity is $25 \%$ lower over the BIA. As a result, specific humidity is much lower over blue ice (Fig. 6c) in daytime. The diurnal cycle of specific humidity over blue ice resembles that of relative humidity, whereas over snow it resembles that of temperature. Apparently, the strong moisture input into the ABL through sublimation is very effectively counteracted by removal through entrainment, as discussed above. Wind speeds over the blue-ice site are slightly less than over the snow site, and peak in daytime. At site 3 , a distinct minimum in wind speed is observed in the late afternoon. Sites 6 and 7 experience a more obvious diurnal cycle in wind speed and direction (not shown), with minimum winds in daytime and maximum in the early morning (Bintanja, 2000a), a clear signature of katabatic forcing. The different wind climate over the BIA is probably due to locally forced circulations (see Bintanja and Van den Broeke, 1995c) and to the absence of katabatic forcing over the BIA (less cooling, no slope). Predominant winds are from the east (see Fig. 2) due to katabatic and synoptic forcing (Bintanja, 2000a), but westerly surface winds are quite common near sites 1 and 2. Obviously, the meteorological conditions over the blue-ice site are quite different from those over adjacent snow-covered regions, for reasons discussed in later sections.

Bintanja (2000b) used a surface energy-balance model to evaluate the surface heat-budget terms (those not measured directly) from observed meteorological quantities at each of the seven sites during the entire 37 day measuring period. It will be briefly described here (for a more thorough description see Bintanja and Van den Broeke, 1995c; Bintanja and others, 1997; Bintanja, 2000b). The surface energy balance can be written as follows:

$$
S+L+\mathrm{SH}_{\mathrm{s}}+\mathrm{LH}_{\mathrm{s}}+G=0,
$$

where $S$ and $L$ are net shortwave and longwave radiation, $\mathrm{SH}_{\mathrm{S}}$ and $\mathrm{LH}_{\mathrm{S}}$ are the turbulent fluxes of sensible and latent heat and $G$ is the subsurface conductive-heat flux. In the model, the "unknown" quantities such as surface temperature and all fluxes that depend on it (turbulent fluxes, outgoing longwave radiation, subsurface fluxes) are calculated progressively in time throughout the measuring period using input of measured ("known") quantities such as net shortwave radiation, incoming longwave radiation and wind speed, temperature and relative humidity at the lowest measuring level (about $0.5 \mathrm{~m}$ ). The turbulent fluxes are evaluated from the profiles between the surface and this level using Monin-Obukhov similarity theory, which takes into account the effects of stability. For this we need values of the surface roughness lengths, which were estimated from the measured wind profiles at sites 1 and 3 (Bintanja, 2000b). Their values are given in Table 1. Additionally, the model consists of equations describing the evolution of surface and subsurface temperature and the penetration of shortwave 

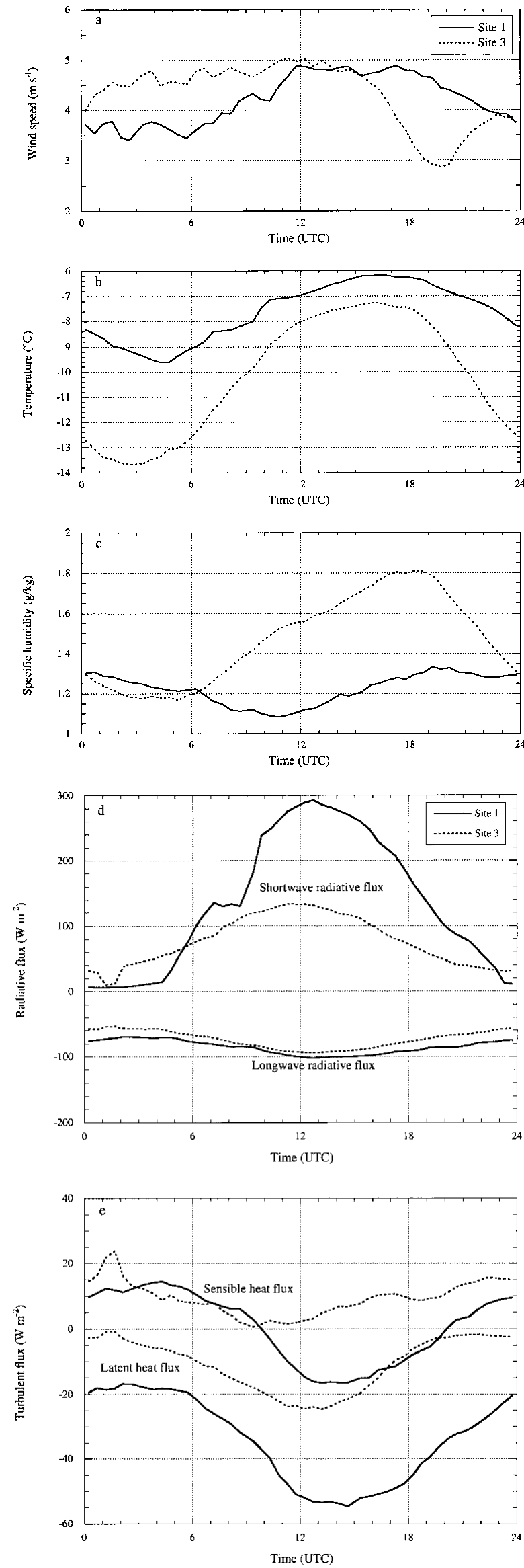

Fig. 6. Mean daily cycles of (a) mean wind speed at $2 \mathrm{~m}$, (b) air temperature at $2 \mathrm{~m},(\mathrm{c})$ specific humidity at $2 \mathrm{~m},(d)$ radiative fluxes at $1.5 \mathrm{~m}$, and (e) turbulent sensible- and latent-heat fluxes over the 37 day measuring period. The heat-budget data were evaluated using a surface energybalance model (Bintanja, 2000b). Fluxes directed towards the surface are taken positive. radiation in the snow or ice. Bintanja (2000b) validates the model at sites 1 and 3, and concludes that the simulated energy balance is fairly accurate.

Net shortwave radiation over blue ice is much larger than over snow because of the lower albedo of blue ice compared to snow (Fig. 6d), even though incident solar radiation is smaller due to shading of the nearby nunataks. Net longwave radiative losses are largest over blue ice, mainly because of its higher surface temperature. The fluxes of sensible and latent heat were calculated in the model, and exhibit significant differences between sites 1 and 3 (Fig. 6e). Conditions over blue ice are significantly less stable than over snow in daytime, resulting in a turbulent transport of sensible heat away from the surface, and a much smaller net sensible-heat flux towards the surface over the full diurnal period. The flux of latent heat (equivalent to surface sublimation) is much larger over blue ice, resulting in larger ablation losses over blue ice compared to the surrounding snowfields. Bintanja (2000b) shows that calculated sublimation at sites 1 and 2 compares well with observed stake readings. Differences in sublimation rate between blue ice (site 1) and snow (site 3) can be attributed to differences in local meteorological conditions and to different characteristics of the surface.

Thus, the relatively high sublimation rate over blue ice can be attributed to the combined effects of wind speed, temperature, humidity, shortwave radiation (mainly albedo), incoming longwave radiation, subsurface shortwave absorption and extinction, and aerodynamic roughness. To find out how each of these different characteristics contributes to the difference in latent-heat flux between blue ice and snow, the surface energy balance (including the latent-heat flux) at site 1 over blue ice was recalculated by subsequently imposing "snow" (site 3) values/characteristics on the various variables:

Case 1. Blue-ice conditions (site 1).

Case 2. Apply meteorological conditions (temperature, humidity and wind speed) of site 3 to case 1 .

Case 3. Apply incoming and reflected shortwave radiative fluxes (specifying the albedo) and incoming longwave radiative flux of site 3 to case 2 .

Case 4. Apply radiative and conductive characteristics (density, shortwave absorption and extinction) typical of snow to case 3 .

Case 5. Apply surface roughness lengths typical of snow to case 4 . Now conditions are equal to those of site 3 (snow).

Cases 2-4 specify hybrid conditions intermediate between blue ice and snow. Figure 7 shows how the sublimation rate changes when each of these changes is subsequently applied. Evidently, applying meteorological conditions (case 2) typical for site 3 at site 1 over blue ice reduces the latent-heat flux by $13 \mathrm{~W} \mathrm{~m}^{-2}$. This is a significant reduction $(30 \%)$, which is caused primarily by the lower temperatures and the undersaturated environment. As a result, the stability is increased while the vertical humidity gradient is reduced. Differences in wind climate contribute only marginally to the difference in sublimation. A further significant reduction in sublimation occurs when snow radiative fluxes are applied (case 3). As a result of mainly the higher albedo and hence the lower solar absorption, the latent-heat flux further diminishes by almost $15 \mathrm{~W} \mathrm{~m}^{-2}$. After these two changes, the latent-heat flux is only $6.6 \mathrm{~W} \mathrm{~m}^{-2}$, about $5 \mathrm{~W} \mathrm{~m}^{-2}$ lower than the latent- 


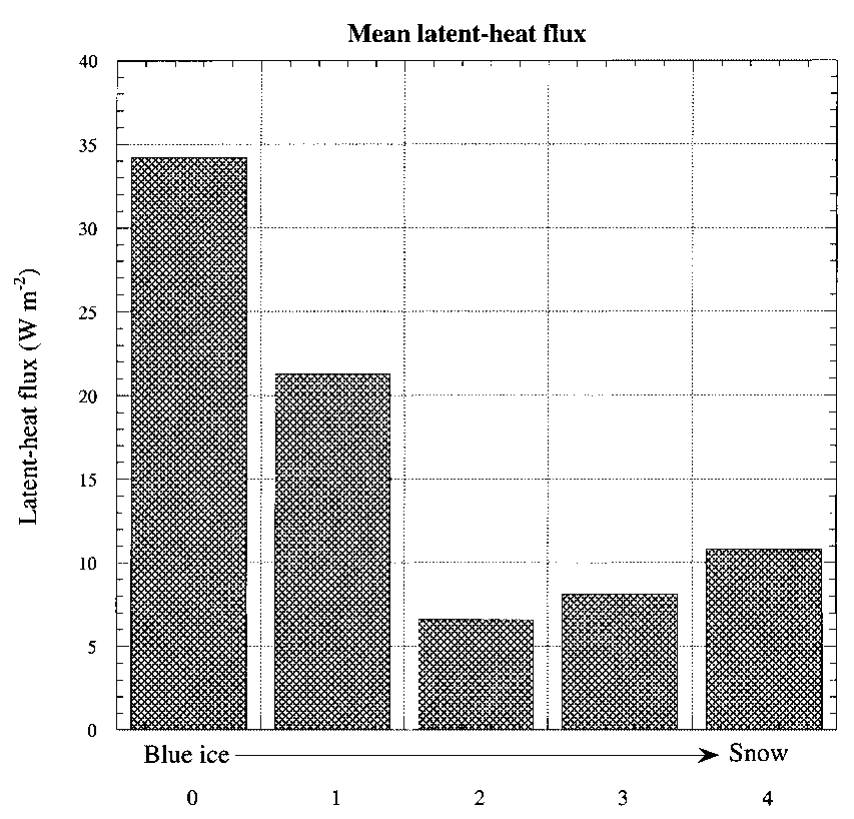

Fig. 7. Mean value of the latent-heat flux over the 37 day period for conditions over blue ice (site 1, case 1), over snow ( site 3, case 5) and for hybrid conditions (cases 2-4; see text). Fluxes directed away from the surface are taken positive.

heat flux at site 3 over snow. The two final sets of changes (cases 4 and 5), which are related to the characteristics of the (sub)surface, act to increase the sublimation rate towards its value over snow. Hence, the fact that snow is aerodynamically rougher than blue ice enhances the latent-heat flux by $2.5 \mathrm{~W} \mathrm{~m}^{-2}$. The conclusion of these simple calculations is that the special meteorological conditions over BIAs (warm and dry) and their combined specific characteristics each explain roughly $50 \%$ of the difference in sublimation rate between blue ice and snow.

\section{ENHANGED TURBULENGE OVER BLUE-IGE AREAS: A CASE-STUDY}

The presence of upwind rocks and nunataks may cause significant turbulent conditions over BIAs due to intermittent vortex shedding and the generation of gravity waves under favourable conditions. This turbulent behaviour is unrelated to the "normal" turbulence generated by the surface of BIAs, and therefore induces additional vertical and horizontal transports of momentum, heat and moisture. The higher variability of winds over BIAs is reflected in much lower values of wind-directional constancy compared to values over snow (Table 1). With respect to the moisture budget this extra upward transport increases the sublimation rate by making the ABL drier. To investigate this phenomenon we performed cable-balloon soundings near site 1 over blue ice during one day (1200 UTC on 26 January to 1200 UTC on 27 January). These and other data gathered during this day will be used as a case-study to illustrate the enhanced turbulent conditions over blue ice. Winds were quite strong and gusty in daytime on 26 January, but conditions calmed in the evening and remained calm thereafter.

To substantiate the effects of turbulence we have analyzed turbulence data measured at $2 \mathrm{~m}$ above the surface at sites 1 and 3. Usually, the turbulent energy in the surface layer is carried by eddies of different sizes and time-scales in the approximate range $0.001-1 \mathrm{~Hz}$. To find out how much energy
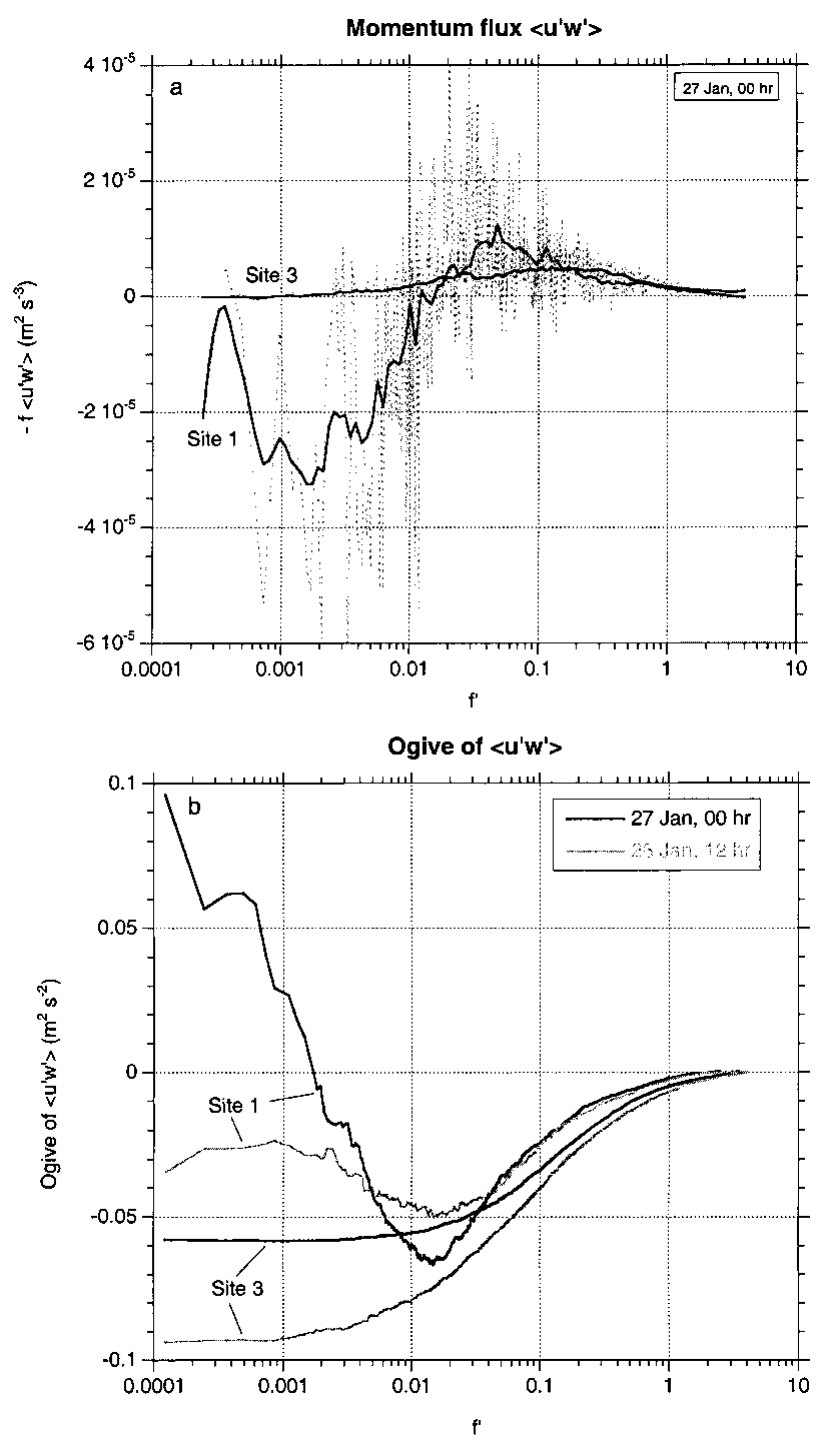

Fig. 8. (a) Spectrum of the momentum flux recorded by the sonic anemometer at $2 \mathrm{~m}$ at sites 1 and 3. Grey lines represent the actual spectrum, while black lines are five-point smoothed fits. (b) Ogives of the momentum flux during the day (grey lines) and the night (black lines) at sites 1 and 3. The ogive represents the amount of energy at frequencies larger than $f^{\prime}(=f z / u)$. Data comprise 1hour. Note the logarithmic scale on the $x$ axis.

is at what scales, a Fourier decomposition of the various variances and covariances has been made for hourly observations made at 1200 and 2400 UTC on 26 January at sites 1 and 3. Figure 8a shows the energy spectrum of the momentum flux $\overline{u^{\prime} w^{\prime}}$. Evidently, over snow at site 3 the energy carried by the long time-scales is negligible, the maximum occurring at $f^{\prime} \sim 0.1 \mathrm{~Hz}\left(f^{\prime}=f z / u\right.$ is the non-dimensional frequency). This is the normal situation, with a spectral gap being present between turbulence and longer-scale variance (Kaimal and Finnigan, 1994). Over blue ice near site 1, on the other hand, the large scales do contribute significantly to the total momentum flux by generating a flux in the opposite direction in this particular case. This can be seen even more clearly in Figure 8b, which presents the ogives of the momentum and moisture fluxes. The ogive at a certain frequency $\left(f_{\mathrm{c}}\right)$ represents the sum of energy carried by eddies with frequencies larger than $f_{\mathrm{c}}$ (Van de Avoird and Duynkerke, 1999). If an ogive converges at low $f^{\prime}$ (i.e. large time-scale), then the contribution of large scales in the turbulent transport is negligible. Clearly, this is the case at site 3 where the 
ogives converge at low $f^{\prime}$. In contrast, the ogives of the turbulent momentum fluxes do not converge at all over blue ice at site 1 (the other fluxes exhibit similar behaviour). This again indicates that large-scale turbulent motions in the form of large eddies and waves, which are very probably induced by the upwind mountains, contribute significantly to the vertical turbulent energy transports over blue ice at site 1 and probably over BIAs in general. Differences in ogives and spectra of turbulence at sites 1 and 3 on other days exhibit qualitatively similar characteristics.

Radiosonde soundings carried out near Svea at 1200 and 2400 UTC on 26 January allow a direct comparison between the vertical profiles over blue ice near site 1 and over snow near Svea. Figure 9a shows how the vertical profiles in specific humidity compare. At 0000 UTC, the boundary layer at site 1 appears to be somewhat drier than
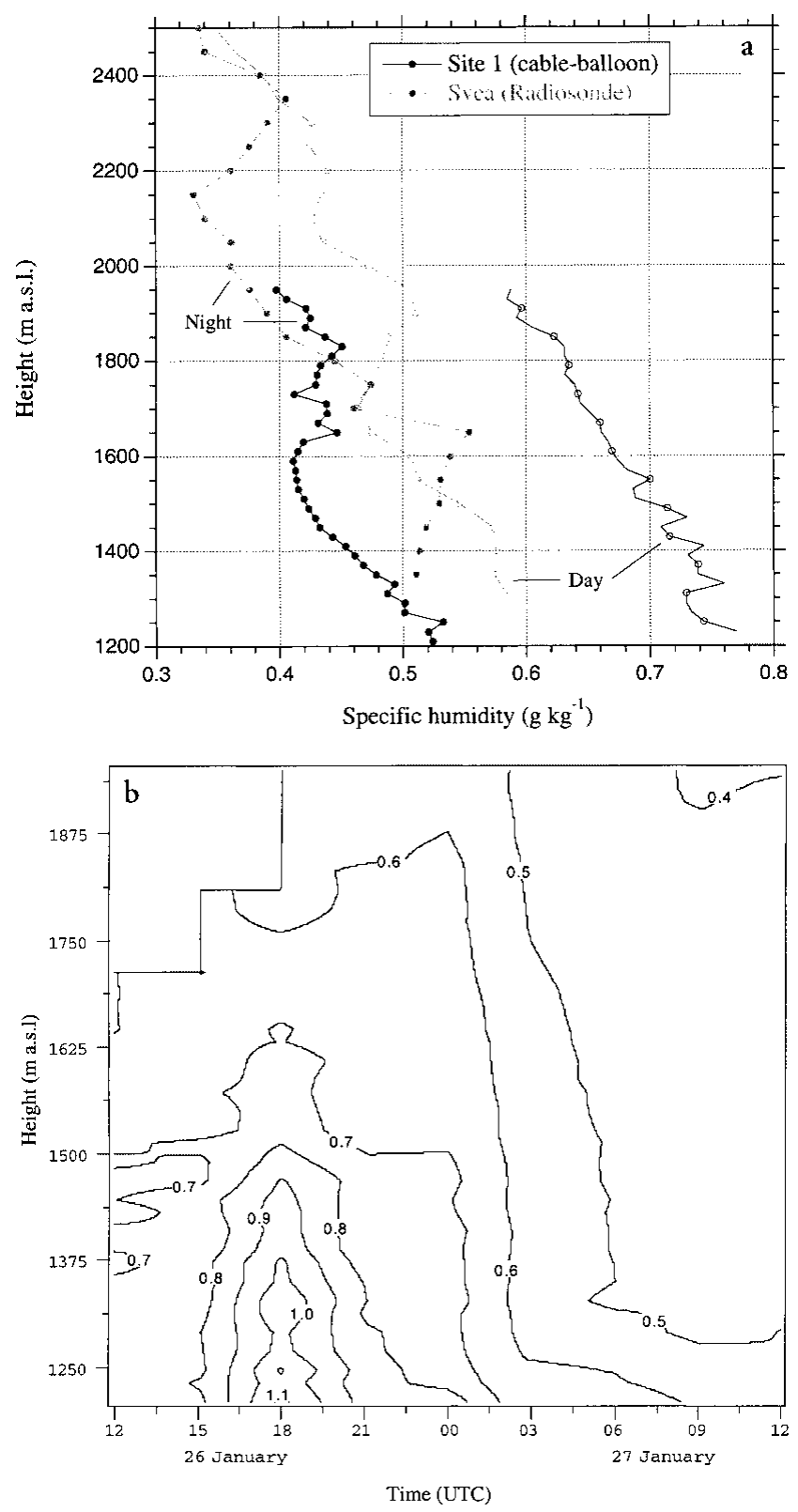

Fig. 9. (a) Vertical profiles of specific humidity measured simultaneously at site 1 using the cable-balloon (black lines) and at Svea by radiosonde (grey lines). Daytime (1200 UTC on 26 January) and night-time (0000 UTC on 27 January) soundings are shown. (b) Temporal variation of the vertical specific humidity profile $\left(\mathrm{g} \mathrm{kg}^{-1}\right)$ at site 1 during one day (1200 UTC on 26 fanuary to 1200 UTC on 27 January). Soundings were taken every $3 \mathrm{~h}$. at Svea, whereas at 1200 UTC the situation is reversed. This can be attributed to the strong sublimation over blue ice, which increases levels of $q$ throughout the boundary layer during the day (at night, moisture is removed either upward or downstream). This can be seen even better in Figure $9 \mathrm{~b}$. The increase in specific humidity during the day can be attributed mainly to the surface sublimation, which then dominates the moisture budget of the ABL. When surface sublimation diminishes, the moist air in the boundary layer is either advected downstream horizontally or is entrained upward into the free atmosphere. The latter is reinforced by the extra turbulence generated by the upwind mountain. This picture of the moisture budget is consistent with the one outlined in section 4 .

\section{PREGIPITATION AND SNOWDRIFTING}

Accumulation over the Antarctic ice sheet occurs mainly through direct precipitation onto the surface. Maximum precipitation rates are generally found near the coast (King and Turner, 1997), with precipitation rates strongly declining towards the high interior. Another potentially important accumulation term is the deposition by snowdrift (in particular locally), although over BIAs snowdrift divergence is usually an ablation term (Takahashi and others, 1988; Van den Broeke and Bintanja, 1995a). Condensation of rime onto the surface may occur occasionally, but is generally regarded as unimportant compared to the other terms. BIAs can exist only if the snow that (occasionally) accumulates onto its surface is readily removed. Obviously, this requirement is satisfied best if precipitation rates are low, which is one reason why BIAs are rarely found close to the coast (disregarding the low-elevation melt-dominated ablation areas). Alternatively, snow-removal mechanisms over BIAs should be very efficient. Snow can be removed either by sublimation or by snowdrift erosion. Removal by sublimation is a relatively slow process, whereas removal by wind erosion can be very quick and efficient.

It seems unlikely that precipitation rates over BIAs are very different from those over nearby snowfields. This is because precipitation is generally caused by mesoscale synoptic systems and orographic lifting, which on average induce precipitation patterns largely unrelated to the presence of BIAs. The small-scale orography that is usually present in the vicinity of BIAs may alter precipitation patterns somewhat by causing selective forced upward motions, but this effect is probably not very important and is difficult to generalize. Since snowdrifting generally induces erosion rather than deposition over BIAs, precipitation is the only candidate to cause significant accumulation over BIAs. Two welldefined events of snow accumulation on BIAs have been recorded so far. Both were detected indirectly by inspecting anomalously high surface albedo values measured at weather stations placed on BIAs. The first was a 2 week period of snow coverage in December 1988 on the Scharffenbergbotnen BIA near site 1, which was seen in data from an AWS deployed by Swedish scientists (Jonsson, 1992; Bintanja and others, 1997). The second occurrence was at site 5 , which was located on a BIA $50 \mathrm{~km}$ southwest of Svea, in summer 1997/98. Figure 10 shows daily surface albedo values for both events. Obviously, the snowfall significantly increased the surface albedo to a value close to that of an unbroken snow surface (0.75-0.80). The reason that it does not quite reach the "snow" values may be related to the fact that the two snowfall events prob- 


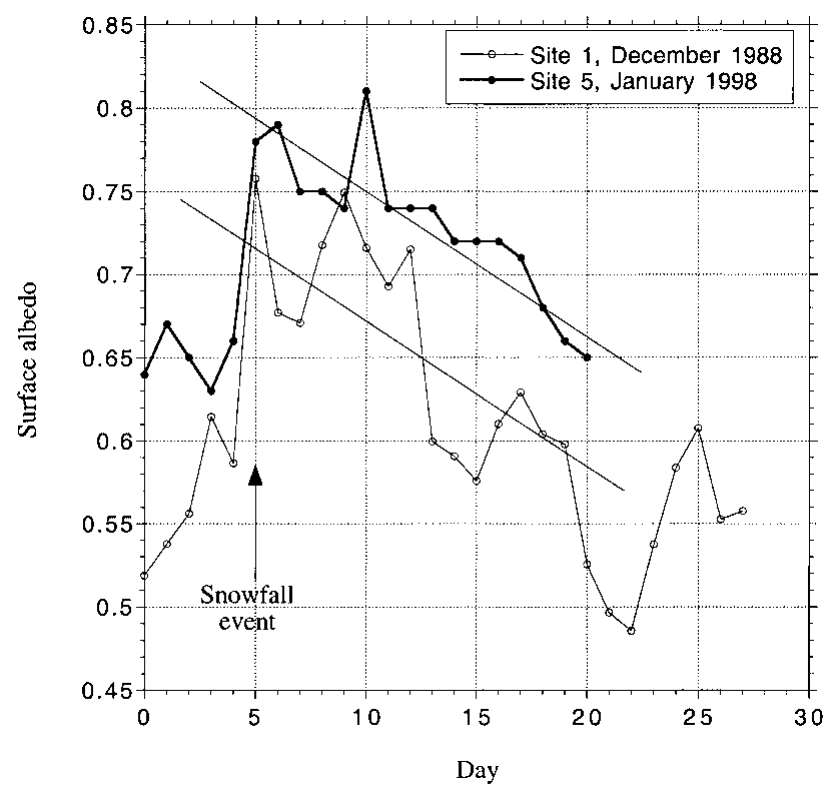

Fig. 10. Daily mean values of surface albedo in two cases when significant snow coverage occurred over blue ice (i.e. at site 1 in December 1988, as recorded by a Swedish AWS, and at site 5 in 1998). The snowfall event is marked by the vertical arrow, and is apparent through a significant increase in surface albedo from the background blue-ice value (0.55-0.65) to a value representative for a snow cover (0.75-0.80). Straight lines indicate the overall trend in decreasing albedo as a result of more or less gradual thinning of the snow cover.

ably resulted in only a thin layer of snow accumulation (a few $\mathrm{cm}$ ). In both cases, the albedo slowly declined at roughly the same rate as blue-ice albedo values in about 2 weeks. This slow decrease suggests a gradual thinning of the snow layer, exposing more and more dark-blue ice-reducing the albedo. This overall gradual thinning, in turn, suggests that in these cases the snow may have been removed mainly through the slow sublimation process. Even though any temporary snow cover on BIAs is readily removed, such events will reduce the net surface mass balance as blue ice is not exposed to ablative mechanisms while being buried under the snow cover.

These two cases occurred during summer. But what happens in winter? One could tentatively argue that the chance of a BIA becoming buried by snow is higher in winter than in summer, since moisture transport to the Antarctic and the associated precipitation amounts generally peak in winter (King and Turner, 1997). Precipitation events tend to coincide with strong winds which, over BIAs, erode the surface from its eventual snow cover. Figure 1la shows direct ablation measurements carried out during 1998 and 1999 using the acoustic height sensor attached to the AWS near site 1. Evidently, no clear sign of significant accumulation events at this location in this period can be detected (although thin layers of snow may have been present in October 1998, February 1999 and April 1999, as indicated by slight increases in surface height). This might suggest that, during winter, winds are sufficiently strong to virtually instantaneously remove all accumulated snow from the BIA. This is even more evident when it is realized that precipitation events usually coincide with strong, synoptically forced winds. Hence, we expect that stronger winds may remove the potentially larger precipitated snow amounts during winter.

Evidently snow accumulation onto the blue-ice surface increases the surface reflectivity. By doing so it reduces the energy available for sublimation, so it takes longer to remove the snow (if snow erosion is disregarded). This tends to reduce the mass balance of BIAs. To estimate how important this effect is, we calculated the sublimation rates at site 5 with the surface energy-balance model introduced earlier (Bintanja, 2000b), (1) using measured albedo values, including the higher values during the snow-cover event, and (2) assuming albedo values typical of blue ice at site $5(0.63)$ during the event. These calculations reveal that the snow cover significantly reduces sublimation rates by $3.9 \mathrm{~W} \mathrm{~m}^{-2}$, which is about $26 \%$ of the total.

Over BIAs, snowdrift is an important mass-balance mechanism. Presumably, it is the mechanism responsible for the formation of BIAs by causing continuous erosion of the surface until bare ice emerges (Takahashi and others, 1988; Van den Broeke and Bintanja, 1995a). The main reason for this is the predominantly gusty, turbulent nature of the wind regime usually found over BIAs. As we saw in section 5, turbulence can be significantly enhanced over the Scharffenbergbotnen BIA owing to the presence of the upwind mountain. Since horizontal snowdrift transport increases with approximately the fifth power of wind speed, strong gusts contribute disproportionally to the snowdrift transport. Hence, snowdrift transport over blue ice near site 1 can be much greater than near site 3 due to the gusts, even though the mean wind speed is about the same (Table 1) (snowdrift transports are also influenced by the irregular topography near site 1). However, recent analysis of snowdrift rates over blue ice near site 1 (Bintanja and others, 2001) has revealed that actual transport rates are usually much smaller over blue ice than over snow, despite the fact that the flow over BIAs is better able to transport snow. This is because the amount of snow to be eroded and transported away is limited over BIAs. Once all snow has been removed, snowdrift transport over BIAs depends only on the amount of snow brought in from the upstream direction; any further increases in wind speed will then not lead to higher transport rates, in contrast to the situation over snow.

An additional variable affecting snowdrift erosion over BIAs is the smoothness of the blue-ice surface. Because of this, snow particles cannot stick to the surface very well and will therefore be eroded in comparatively light winds. This is confirmed by the snowdrift observations performed over the Scharffenbergbotnen BIA (Bintanja and others, 2001), which have revealed that the threshold in shear stress for snowdrift initiation over blue ice may be much smaller than over snow. This fact, and the stronger gusts over BIAs, allow the winds to quickly erode any accumulated snow off the blue ice.

Figure 12a shows potential vertically integrated snowdrift transports $(Q)$ calculated with the empirical transport formula of Takahashi (1985) $\left(Q=7.18 \times 10^{-7} u^{5.17}\right.$ in $\mathrm{kg} \mathrm{m}^{-1} \mathrm{~s}^{-1}$, with $u$ the wind speed at $1 \mathrm{~m}$ ) for half-hourly wind-speed data measured at the sites along the transect. Clearly, snowdrift transports are dominated by the stormy period 8-10 January, when wind speeds were strongest over blue ice at sites 1 and 2 . Hence, even though the average wind speeds do not differ much at the various sites, potential snowdrift transport is highest over the BIA, where the strongest gusts occur. This can also be inferred from Figure 12b, which shows that the highest totals of potential snowdrift transport occur at sites 1 and 2 over blue ice. Excluding the stormy period shows that most snowdrift occurs at site 7 where the highest average winds are found. This indicates that storm events contribute strongly to the erosion of BIAs.

The applied formula for snowdrift transport was derived 

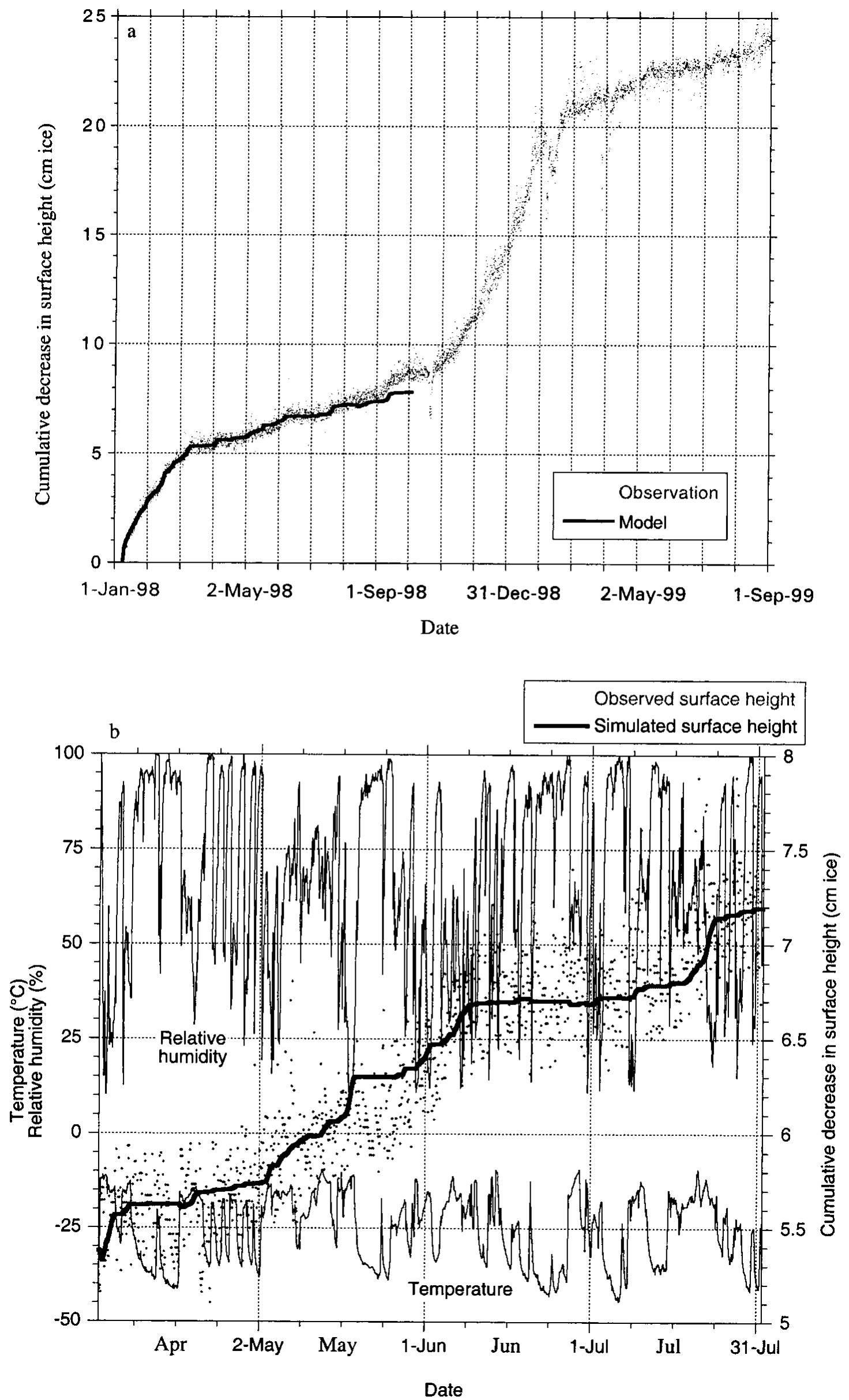

Fig. 11. (a) Measured (dots) and simulated (bold line) cumulative decrease in surface height at site 1 using data recorded at the AWS during 1998 and part of 1999. The station stopped providing reliable meteorological data on 30 September 1998, which restricted the energy-balance and ablation calculations to the first 9 months. (b) Detailed view of cumulative measured (dots) and calculated (bold line) decrease in surface height and concurrent temperature and relative humidity data (thin lines) during austral winter 1998. Wintertime ablation is restricted to short-term warm and dry periods. 
Table 1. Differences in meteorological conditions, surface roughness heights and surface heat fluxes between blue ice (site 1) and snow (site 3)

\begin{tabular}{|c|c|c|}
\hline & Blue ice & Snow \\
\hline Elevation (m a.s.1.) & 1180 & 1170 \\
\hline Air temperature $2 \mathrm{~m}\left({ }^{\circ} \mathrm{C}\right)$ & -7.6 & -10.2 \\
\hline Relative humidity $2 \mathrm{~m}(\%)$ & 49.4 & 70.1 \\
\hline Specific humidity $2 \mathrm{~m}\left(\mathrm{~g} \mathrm{~kg}^{-1}\right)$ & 1.22 & 1.47 \\
\hline Wind speed $2 \mathrm{~m}\left(\mathrm{~m} \mathrm{~s}^{-1}\right)$ & 4.2 & 4.3 \\
\hline Wind-directional constancy & 0.58 & 0.85 \\
\hline Surface albedo & 0.58 & 0.79 \\
\hline Roughness length for momentum (m) & $1 \times 10^{-4}$ & $1 \times 10^{-3}$ \\
\hline Scaler roughness length $(\mathrm{m})$ & $1 \times 10^{-4}$ & $1 \times 10^{-4}$ \\
\hline Net shortwave radiative flux $\left(\mathrm{W} \mathrm{m}^{-2}\right)$ & 135.4 & 75.9 \\
\hline Net longwave radiative flux $\left(\mathrm{W} \mathrm{m}^{-2}\right)$ & -85.3 & -73.7 \\
\hline Net radiative flux $\left(\mathrm{W} \mathrm{m}^{-2}\right)$ & 50 & 2.3 \\
\hline Turbulent sensible flux $\left(\mathrm{W} \mathrm{m}^{-2}\right)$ & 0.4 & 9.3 \\
\hline Turbulent latent flux $\left(\mathrm{W} \mathrm{m}^{-2}\right)$ & -34.2 & -10.8 \\
\hline Net subsurface flux $\left(\mathrm{W} \mathrm{m}^{-2}\right)$ & -16.2 & -0.8 \\
\hline
\end{tabular}

Notes: Fluxes directed towards the surface are taken positive. Data represent averages over the 37 day measuring period (28 December 1997 to 2 February 1998).

over snow, and therefore gives a good indication of the snowdrift transport rates at the various snow sites. Over blue ice, however, snowdrift transports are usually much smaller than the potential snowdrift rates predicted by the empirical formula. This indicates that snowdrift is not saturated, i.e. the shear stress applied by the wind carries fewer particles than it is able to (Bintanja and others, 2001), so the winds normally occurring over BIAs are more than capable of keeping the bare ice surface free of snow by erosion. A simple calculation confirms this. If summer potential snowdrift transport rates as shown in Figure 12b are applied over an entire year, then the potential erosion by snowdrift over the $2.5 \mathrm{~km}$ stretch of blue ice between sites 1 and 2 would amount to about $22 \mathrm{~cm}$ w.e. $\mathrm{a}^{-1}$ (the actual value may be larger because of the higher winds during winter). This is about twice as much as the accumulation recorded at stakes over nearby snowfields (Jonsson, 1992) (which largely represent precipitation), which means that all precipitated snow over the BIA can easily be removed by snowdrift erosion alone. Hence, the local orographic situation of BIAs (upwind rocks) generally induces meteorological conditions (strong gusts, channelling of flow) favourable to strong snowdrift erosion, which in itself would be sufficient to prohibit long-term accumulation of snow onto the blue-ice surface. Mountain blocking, forcing the surface flow and snowdrift to go around the mountain, may be an additional mechanism to explain local divergence of snowdrift over BIAs located in the lee of mountains. In the case of the Scharffenbergbotnen BIA, this blocking effect is probably not very important, as may be inferred from the transect elevation profiles (Fig. 3).

\section{THE NET SURFAGE MASS BALANGE OF BLUE- ICE AREAS}

This section discusses how the surface mass balance of BIAs varies spatially and temporally. To do so, we have to rely on observations of the surface mass balance, which are commonly made by stakes. Annual stake measurements have been made at several BIAs, and are compiled by Bintanja (1999). He shows that annual net mass loss at BIAs decreases from $20-30 \mathrm{~cm}$ w.e. at sea level to about $5 \mathrm{~cm}$ w.e. at $2000 \mathrm{~m}$ a.s.l. Since accumulation is zero, this can be attributed mainly to spatial differences in sublimation (minor contributions from surface melt at some low-altitude BIAs cannot be excluded). This, in turn, can be explained by the fact that sublimation diminishes with decreasing temperature, as explained by Bintanja and others (1997). Hence, on a continental scale the annual mean surface mass balance of BIAs depends primarily on the ambient temperature, and therefore on their altitude.

The surface mass balance inherently varies spatially over the surface of each BIA from a maximum value at a location furthest away from the surrounding snowfields to zero at the border with the surrounding snow (the equilibrium line). At the Scharffenbergbotnen BIA a dense net of stakes was measured regularly (Jonsson, 1992; Näslund, 1992), which showed that ablation rates were maximum at about $15 \mathrm{~cm}$ w.e. $\mathrm{a}^{-1}$ in the easternmost part of the blue-ice field near site 1 where conditions (warm, dry) are most favourable for high sublimation rates (Bintanja and van den Broeke, 1995c; Bintanja, 2000b). Moreover, these data show that annual ablation rates decrease fairly gradually to zero at the equilibrium line. Apparently, meteorological conditions become increasingly less favourable for high sublimation rates towards the equilibrium line (the albedo usually diminishes due to the occurrence of snowpatches on the blue ice). The stake measurements made in summer 1997-98 showed that summer ablation rates at site 2 near the margin of the BIA were indeed somewhat smaller than at site 1 . Incidentally, summertime ablation rates were probably underestimated, as stake measurements over a rippled surface represent the ablation of the crests only. Bintanja and Reijmer (unpublished information) show that this can lead to underestimation of the ablation by $5-10 \%$, since troughs experience the highest sublimation rates (representing $\mathrm{cm}$-scale spatial variations in sublimation). According to Mellor and Swithinbank (1989), most BIAs exhibit a rippled or scalloped surface.

How does the surface mass balance of BIAs vary temporally? If we disregard the occasional short-term coverage of BIAs by snow discussed above, the main mechanism governing temporal variations is obviously sublimation. As a result, ablation rates peak in summer, as sublimation rates are highest in warm conditions. This was demonstrated clearly by Bintanja and others (1997), who calculated sublimation rates from AWS data near site 1 for $>1$ year (1988-89) and showed that sublimation rates are maximum in summer and very low during winter. They were unable to explain the observed annual ablation rates, however, as the apparent wintertime ablation was unaccounted for by the simulated winter sublimation rates. Bintanja (1999) concluded that the issue of wintertime ablation on BIAs remained unsolved.

The AWS data collected during part of 1998 (the AWS stopped functioning on 30 September 1998) allow us to assess this problem, in particular since we now have a highresolution time series of surface ablation provided by the acoustic height sensor. Using the energy-balance model discussed earlier, we have calculated the surface energy balance, including the sublimation rate, at the AWS (near site 1) for the period January-September 1998 for which meteorological data are available. In Figure 1la we compare the calculated cumulative sublimation rate with the changes in surface height recorded by the acoustic sensor. The agreement is very good. As expected, the highest sublimation rates are found in summer. The summer period lasts until early 

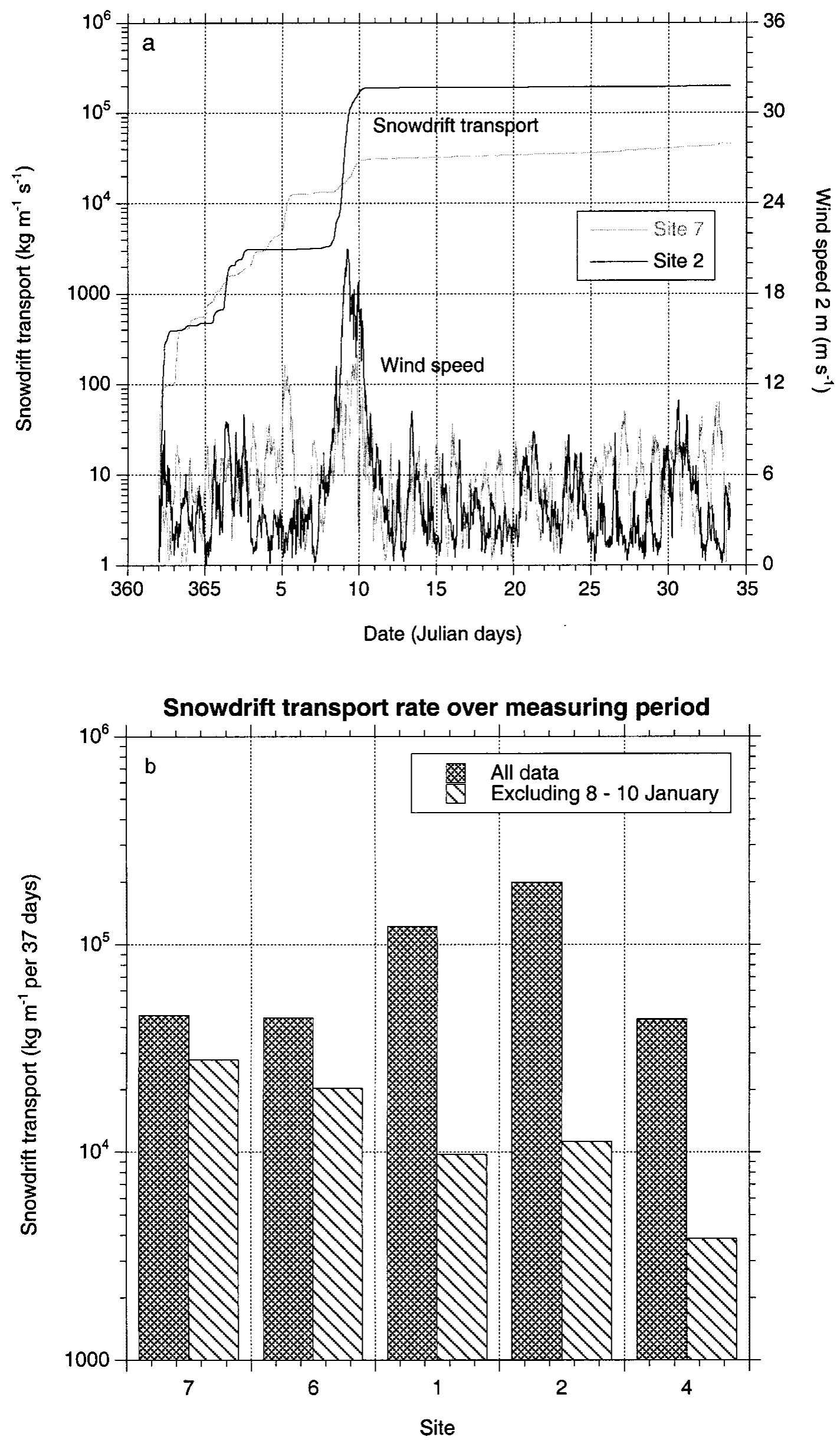

Fig. 12. (a) Cumulative snowdrift transport and wind-speed data at site 2 over blue ice (black lines) and at site 7 over snow ( grey lines) over the 37 day measuring period in summer 1997/98. (b) Total snowdrift transport rates over the 37 day measuring period at the sites along the east-west transect ( see Fig. 5). Light-grey columns indicate snowdrift transport totals if the stormy period of 8-10 January is excluded. 
March, with $5 \mathrm{~cm}$ ablation in 2 months, after which sublimation rates decrease. However, they do not diminish to zero, as would have been expected from the results of Bintanja and others (1997). Instead, ablation continues at a rate of about $4 \mathrm{~cm}$ during the following 8 month winter period. Hence, wintertime ablation rates are about five times smaller than summer ablation on the Scharffenbergbotnen BIA. This difference between summer and winter BIA ablation rates agrees roughly with those estimated by Faure and Buchanan (1991) and Takahashi and others (1992), indicating that nonzero wintertime ablation rates over BIAs may be a general feature. At site 1 , about $10 \mathrm{~cm}$ ablation occurs during the 4 month summer period (November-February), and about $4 \mathrm{~cm}$ during the 8 month winter period. This totals to $14 \mathrm{~cm}$ ice per year, which agrees with the observed stake readings of Näslund (1992).

It is of interest to inspect the wintertime ablation in somewhat more detail (Fig. 1lb). Most of the ablation during winter appears to occur in a few well-defined events, which are generally captured well by the surface energy-balance model. Figure 1lb shows air temperature and relative humidity (RH corrected by the method of Anderson (1994)); highsublimation events are characterized by relatively warm and dry conditions, with strong föhn-like winds. Evidently, such conditions are very favourable for high sublimation rates. Typical examples of such events occur around 20 May, 7 June and 22 July. Clow and others (1988) and Jonsson (1992) were the first to mention the importance of these föhn-like events for wintertime sublimation. The extreme magnitude of these wintertime variations in temperature and relative humidity as shown in Figure 1lb may in large part be caused by the specific orographic setting of the Scharffenbergbotnen BIA, as discussed before. The origins of these seeminglquasiregular events may be related to the triggering of strong katabatic winds by favourable synoptic pressure gradients, as discussed by Jonsson (1992). Whatever their cause may be, they apparently occur widely and quasi-regularly, thereby contributing significantly to the wintertime sublimation over BIAs. Similar but less extreme conditions may cause some sublimation in winter over snow-covered regions as well. The reasons why Bintanja and others (1997) were unable to simulate winter sublimation events may be related to the quality of the meteorological data and to the specific model settings they applied.

\section{GONGLUDING REMARKS}

This paper discusses the meteorological conditions over Antarctic blue-ice areas in relation to the surface mass balance on the basis of an extensive and detailed meteorological and glaciological dataset collected during 37 days in austral summer 1997/98. The measurements were carried out on and near the BIA in the Scharffenbergbotnen valley close to Svea. The main findings can be summarized as follows:

(1) The air over BIAs is warmer than over a snow site adjacent to the BIA at the same elevation, and has a lower relative humidity. The average wind speed over blue ice is the same as over snow, but it exhibits relatively strong gusts and relatively high variability.

(2) Over BIAs, surface sublimation causes negative surface mass balance and is significantly higher than over snow. Roughly half of the difference is due to the different meteorological conditions (warm and dry), while the other half is caused by the specific characteristics of blue ice compared to snow (mainly its lower albedo).

(3) The relatively high temperature and low relative humidity values observed over BIAs can be attributed to adiabatic warming of the descending katabatic flow, aided by diabatic warming due to radiation and by entrainment of warm air from aloft into the boundary layer. These meteorological conditions contribute to the high sublimation rates and hence to the relatively high specific humidity values over blue ice. This additional moisture by sublimation is effectively removed by entrainment and horizontal advection, which exhibit maximum values over BIAs.

(4) Strong turbulent conditions over BIAs generated by the upwind mountains show up as low-frequency fluctuations in the various fluxes. These enhance the vertical turbulent transport of, for instance, moisture, and thereby contribute to the rapid removal of the large amounts of moisture in the boundary layer over BIAs.

(5) Two examples (using time series of surface albedo measurements) showed that occasional snow accumulation onto BIAs was removed within 2 weeks.

(6) Potential snowdrift transport rates over blue ice are larger than over snow due to the larger peak winds and gusts occurring over BIAs. On the Scharffenbergbotnen BIA, annual precipitation can easily be removed by snowdrift erosion alone.

(7) Sublimation rates clearly peak in summer, when temperatures are highest. However, wintertime sublimation occurring during relatively warm and dry föhn-like events cannot be neglected, as $30 \%$ of the annual ablation takes place during winter over the Scharffenbergbotnen BIA. Calculations of sublimation rates using AWS data confirm this.

It should again be noted that the results presented here are applicable only for BIAs located in the lee of a mountain. Over other types of BIAs, such as those close to the Yamato Mountains which seem to be largely unrelated to the presence of upwind mountains, meteorological characteristics may be different from those described here. Consequently, many of the mechanisms described here may not apply to other types of BIAs.

\section{ACKNOWLEDGEMENTS}

We would like to thank H. Snellen and the other members of the SWEDARP 1997/98 expedition to Svea and Wasa for their invaluable help with the meteorological part of the field campaign. We are grateful to J. Sievers of the Institut für Angewandte Geodäsie in Frankfurt, Germany, for making available the DEM data of the Heimefrontfjella region. The thorough reviews of I. Allison and S. Takahashi helped to improve the paper. Financial support was provided by the Netherlands Antarctic Research Programme (ALW), which is part of the Netherlands Organization of Scientific Research (NWO). Funding was obtained in the framework of the European Project for Ice Coring in Antarctica.

\section{REFERENGES}

Anderson, P. S. 1994. A method for rescaling humidity sensors at temperatures well below freezing. F. Atmos. Oceanic Technol., 11(5), 1388-1391. 
Bintanja, R. 1999. On the glaciological, meteorological and climatological significance of Antarctic blue ice areas. Rev. Geophys., 37(3), 337-359.

Bintanja, R. 2000a. Mesoscale meteorological conditions in Dronning Maud Land, Antarctica, during summer: a qualitative analysis of forcing mechanisms. 7. Appl. Meteorol., 39, 2348-2370.

Bintanja, R. 2000b. The surface heat budget of Antarctic snow and blue ice: interpretation of temporal and spatial variability. 7. Geophys. Res., 105, 24,387-24,407

Bintanja, R. and M. R. van den Broeke. 1995a. The climate sensitivity of Antarctic blue-ice areas. Ann. Glaciol., 21, 157-161.

Bintanja, R. and M. R. van den Broeke. 1995b. Momentum and scalar transfer coefficients over aerodynamically smooth Antarctic surfaces. Boundary-Layer Meteorol., 74(1-2), 89-111.

Bintanja, R. and M. R. van den Broeke. 1995c. The surface energy balance of Antarctic snow and blue ice. F. Appl. Meteorol., 34(4), 902-926.

Bintanja, R., S. Jonsson and W. H. Knap. 1997. The annual cycle of the surface energy balance of Antarctic blue ice. 7. Geophys. Res., 102(D2), 1867-1881.

Bintanja, R., C. H. Reijmer, H. Snellen and M. P. A. Thomassen. 1998. Meteorological and glaciological investigations on a blue ice area in the Heimefrontfjella, Dronning Maud Land, Antarctica: the follow-up of the 92-93 experiment. Utrecht, Utrecht University. Institute for Marine and Atmospheric Research. (1997-98 field report.)

Bintanja, R., H. Lilienthal and H. Tüg. 2001. Observations of snowdrift over Antarctic snow and blue-ice surfaces. Ann. Glaciol., 32, 168-174.

Cassidy, W. A., R. Harvey, J. Schutt, G. DeLisle and K. Yanai. 1992. The meteorite collection sites of Antarctica. Meteoritics, 27(5), 490-525.

Glow, G. D., G. P. McKay, G. M. Simmons, Jr and R. A. Wharton, Jr. 1988. Climatological observations and predicted sublimation rates at Lake Hoare, Antarctica. 7. Climate, 1 (7), 715-728.

Faure, G. and D. Buchanan. 1991. Ablation rates of the ice fields in the vicinity of the Allan Hills, Victoria Land, Antarctica. In Elliot, D. H., ed. Contributions to Antarctic research II. Washington, DC, American Geophysical Union, 19-31. (Antarctic Research Series 53.)

Fireman, E. L. 1989. The Lewis Cliff meteorite stranding area, polar ice cores and Wisconsin period impacts. Lunar and Planetary Science, 21, 365-366.

Jonsson, S. 1992. Local climate and mass balance of a blue-ice area in western Dronning Maud Land, Antarctica. Z. Gletscherkd. Glazialgeol., 26(1), 1990, $11-29$.

Kaimal, J. C. and J. J. Finnigan. 1994. Atmospheric boundary layer flows: their structure and measurement. Oxford, etc., Oxford University Press.

King, J. C. and J. Turner. 1997. Antarctic meteorology and climatology. Cambridge, Cambridge University Press.
Kodama,Y., G. Wendler and N. Ishikawa. 1989. The diurnal variation of the boundary layer in summer in Adelie Land, East Antarctica. 7. Appl. Meteorol., 28(1), 16-24.

Mellor, M. and C. Swithinbank. 1989. Airfields on Antarctic glacier ice. CRREL Rep. 89-21.

Näslund, J.-O. 1992. Blue-ice investigations in the Scharffenbergbotnen basin. In Melander, O. and M. L. Carlsson, eds. Swedish Antarctic Research Programme 1991/92. Stockholm, Swedish Polar Research Secretariat, 48-53. (Cruise Report.)

Nishiizumi, K. and 7 others. 1989. Age of Allan Hills 82102, a meteorite found inside the ice. Nature, 340(6234), 550-552.

Takahashi, S. 1985. Characteristics of drifting snow at Mizuho Station, Antarctica. Ann. Glaciol., 6, 71-75.

Takahashi, S., R. Naruse, M. Nakawo and S. Mae. 1988. A bare ice field in east Queen Maud Land, Antarctica, caused by horizontal divergence of drifting snow. Ann. Glaciol., 11, 156-160.

Takahashi, S., T. Endoh, N. Azuma and S. Meshida. 1992. Bare ice fields developed in the inland part of Antarctica. Proc. NIPR Symp. Polar Meteorol. Glaciol. 5, 128-139.

Tüg, H. 1988. A pulse-counting technique for the measurement of drifting snow. Ann. Glaciol., 11, 184-186.

Van de Avoird, E. and P. G. Duynkerke. 1999. Turbulence in a katabatic flow. Does it resemble turbulence in stable boundary layers over flat surfaces? Boundary-Layer Meteorol., 92, 39-66.

Van den Broeke, M. R. 1996. The atmospheric boundary layer over ice sheets and glaciers. (Ph.D. thesis, Universiteit Utrecht. Faculteit Natuur- en Sterrenkunde.)

Van den Broeke, M. R. 1997. Spatial and temporal variation of sublimation on Antarctica: results of a high-resolution general circulation model. 7 . Geophys. Res., 102(D25), 29,765-29,777.

Van den Broeke, M. R. and R. Bintanja. 1995a. The interaction of katabatic winds and the formation of blue-ice areas in East Antarctica. F. Glaciol., 41 (138), 395-407.

Van den Broeke, M. R. and R. Bintanja. 1995b. Summertime atmospheric circulation in the vicinity of a blue ice area in east Queen Maud Land, Antarctica. Boundary-Layer Meteorol., 72(45), 411-438.

Van Roijen, J. J., K. van der Borg, A. F. M. de Jong and J. Oerlemans. 1995. Ages and ablation and accumulation rates from ${ }^{14} \mathrm{C}$ measurements on Antarctic ice. Ann. Glaciol., 21, 139-143.

Whillans, I. M. and W. A. Cassidy. 1983. Catch a falling star: meteorites and old ice. Science, 222(4619), 55-57.

MS received 24 February 2000 and accepted in revised form 6 November 2000 